\title{
Random Sample Population
}

National Cancer Institute

\section{Source}

National Cancer Institute. Random Sample Population. NCI Thesaurus. Code C142662.

The target group that is chosen via a sampling methodology created to provide an equal probability of being chosen. 